\title{
Generation of "nanometer-size aggregates" using Solubility Controlling Peptide tags and their ability to increase a protein's immunogenicity in vivo
}

Nafsoon Rahman ${ }^{1 *}$, Mohammad Monirul Islam ${ }^{2 *}$, Satoru Unzai ${ }^{3}$, Shiho Miura ${ }^{1}$, Yutaka Kuroda $^{1 \#}$

${ }^{1}$ Department of Biotechnology and Life Sciences, Graduate School of Engineering, Tokyo University of Agriculture and Technology, 2-24-16 Nakamachi, Koganei-shi, Tokyo 1848588, Japan. ${ }^{2}$ Department of Biochemistry and Molecular Biology, University of Chittagong, Chittagong-4331, Bangladesh. ${ }^{3}$ Department of Frontier Bioscience, Faculty of Bioscience and Applied Chemistry, Hosei University, 3-7-2 Kajino-cho, Koganei, Tokyo 184-8584, Japan.

\section{*Equal contribution}

\section{\#Correspondence to Y.K.}

Email: ykuroda@cc.tuat.ac.jp Telephone/Fax: +81-42-388-7794

Running Title: Generation of "nanometer-size aggregates" using Solubility Controlling Peptide tags and their ability to increase a protein's immunogenicity in vivo

Manuscript information: 30 Pages; 3 Tables; 4 Figures

Keywords: SCP-tag (solubility controlling peptide tag), Oligomers, Soluble aggregates, Hydrodynamic radius, Antibody titer, ELISA

Abbreviations: BPTI: Bovine Pancreatic Trypsin Inhibitor, CD: Circular Dichroism, DLS: Dynamic Light Scattering, SCP-tags: Solubility Controlling Peptide tags; SLS: Static Light Scattering; AUC: Analytical Ultra Centrifugation; ELISA: Enzyme-Linked Immunosorbent Assay

Nomenclature: SCP-tags: solubility controlling peptide tags; We use "aggregates" and “oligomer" interchangeably. Sub-visible aggregates/oligomers: Aggregates/oligomers <100 $\mu \mathrm{m}$ that are not visible to the naked eye and remain in the soluble fraction upon 
centrifugation; BPTI-19A (untagged BPTI-19A): A simplified variant of bovine pancreatic trypsin inhibitor containing 19 alanines; BPTI-C5X: 5 amino acid residues as SCP-tags added at the C-terminus of BPTI, where X stands for amino acid identity. 


\begin{abstract}
(150 words)
Sub-visible aggregates of proteins are suspected to cause adverse immune response, and a recent FDA guideline has recommended the monitoring of micrometer-size aggregates (2-10 $\mu \mathrm{m})$ though recognizing that the underlying mechanism behind aggregation and immunogenicity remains unclear. Here, we report a correlation between the immunogenicity and the size of nanometer-scale aggregates of a small $6.5 \mathrm{kDa}$ model protein, Bovine Pancreatic Trypsin Inhibitor (BPTI) variant. BPTI-19A, a monomeric and non-immunogenic protein, was oligomerized into sub-visible aggregates with hydrodynamic radii $\left(R_{\mathrm{h}}\right)$ of $3 \sim 4 \mathrm{~nm}$ by attaching hydrophobic solubility controlling peptide (SCP) tags to its C-terminus. The results showed that the association of non-immunogenic BPTI into nanometer-size aggregates made it highly immunogenic, as assessed by the IgG antibody titers of the mice's sera. Overall, the study emphasizes that sub-visible aggregates, as small as a few nanometers, which are presently ignored, are worth monitoring for deciphering the origin of undesired immunogenicity of therapeutic proteins.
\end{abstract}




\section{Introduction}

Therapeutic proteins such as monoclonal antibodies, hormones, and other recombinant protein drugs are increasingly used for the treatment of various types of human diseases. However, protein aggregation, causing unwanted immunogenicity against therapeutic proteins ${ }^{\mathbf{1 , 2}}$ and in turn decreasing therapeutic efficacy through the production of anti-drug antibodies, has occasionally been reported ${ }^{3-5}$. In general, monomeric proteins in any state (native, partially unfolded, or unfolded) may form aggregates of diverse sizes ranging from tiny sub-visible aggregates to visible precipitates with various biophysical properties ${ }^{6-9}$. Hence, it is worth exploring the nature of the relationship between the aggregates and the protein's immunogenicity from a biophysical perspective.

A link between the aggregation of therapeutic proteins and immunogenicity has long been speculated and has been documented especially for micron-size sub-visible aggregates ${ }^{\mathbf{1 0 - 1 3}}$ For example, in vitro experiments indicated that $2-10 \mu \mathrm{m}$ sized sub-visible aggregates of human monoclonal antibodies increased the production of naïve peripheral blood mononuclear cells ${ }^{\mathbf{1 4}}$. Likewise, Trastuzumab (a monoclonal antibody) with less than $3 \%$ of $\sim 2 \mu \mathrm{m}$ sub-visible aggregates, caused $\mathrm{T}$-cell proliferation in vitro ${ }^{15}$. In vivo investigations are less common, and experiments using mice models showed that sub-visible aggregates of a humanized $\mathrm{ScFv}$ generated immunogenicity ${ }^{\mathbf{1 6}, 17}$. However, other immunization studies revealed that aggregates of antibodies 18 or proteins ${ }^{19}$ are not always immunogenic. One factor behind the lack of consistency is that the micron-aggregates are induced by chemical and physical stresses $\mathbf{2 0 , 2 1}$ making it difficult to control their biophysical characteristics. Furthermore, the aggregates assessed in samples are different from the injected ones ${ }^{\mathbf{2 1 , 2 2}}$ or in many other reports the sizes are not measured at all 23-25. As a consequence, the biophysical properties (structure, stability, conformation, etc.) of aggregates responsible for the increased immune response are yet to be fully elucidated $\mathbf{1 , 1 3 , 1 7 , 2 1}$.

Recently, the European Medicines Agency (EMA) considered visible and sub-visible aggregates as risk factors for unwanted immunogenicity of therapeutic proteins in their safety guidelines ${ }^{\mathbf{2 6}}$. Likewise, the Food and Drug Administration (FDA) recommended the screening and minimizing of sub-visible aggregates within 2-10 $\mu \mathrm{m}$ ranges ${ }^{27}$. These recommendations are based on several clinical reports suspecting that aggregates of therapeutic proteins might have caused adverse immune response. However, clinical case reports are inherently contextual and often put little emphasis on the biophysical properties of the therapeutic proteins ${ }^{28-30}$. 
Additionally, the immune response generated by protein aggregates smaller than $2 \mu \mathrm{m}$ is practically un-investigated, due to technical burdens for identifying and measuring them.

In previous reports, we showed, using BPTI-19A as a model protein (58 residues; MW: 5.98 $\mathrm{kDa}$ ), that one can manipulate a protein's solubility ${ }^{\mathbf{3 1 - 3 3}}$, aggregation kinetics ${ }^{\mathbf{3 4}}$ and aggregate sizes ${ }^{35}$ by using a solubility controlling peptide tag (SCP-tag). The advantage of the SCP-tags is that we can control the size and properties of the aggregates rather accurately and that the tags do not affect or barely affects the thermodynamic properties, structure, and function of the native protein ${ }^{32,33,36}$. In this study, we investigated the immunogenicity of BPTI-19A that were oligomerized into nanometer-sized sub-visible aggregates by attaching hydrophobic SCP-tags (C5A, C5V, C5L and C5I). As a result, the untagged BPTI-19A was not immunogenic as assessed by IgG ELISA against BPTI-19A, but a minute increase of the hydrodynamic radius to $\sim 4 \mathrm{~nm}$, which was generated by attaching a C5I tag to BPTI-19A, increased its immunogenicity by up to 66 folds. These observations indicate that nanometer-size aggregates, which are much smaller than currently examined aggregates and that are difficult to remove by filtration/centrifugation as used in standard biomedical practices, can significantly increase the immunogenicity of a therapeutic protein. 


\section{Results and Discussion}

\section{Oligomerization of BPTI-19A using SCP-tags}

The size of the aggregates was measured by dynamic light scattering at both 25 and $37^{\circ} \mathrm{C}$. The samples were prepared in PBS, kept for 20 minutes at $25^{\circ} \mathrm{C}$, and centrifuged at $20,000 \mathrm{xg}$ for 20 minutes at $25^{\circ} \mathrm{C}$ to remove large particles if any (see Materials and Methods for details). The concentrations of the BPTI variants remained nearly unchanged upon centrifugation or filtration with a $0.2 \mu \mathrm{m}$ Minisart filter (Supplementary Figure S1a), confirming that only submicron and soluble aggregates were present in the samples. The $R_{\mathrm{h}}$ of the untagged BPTI-19A, $\mathrm{C} 5 \mathrm{~A}$, and $\mathrm{C} 5 \mathrm{~V}$ tagged variants at $25^{\circ} \mathrm{C}$ were $1.33 \pm 0.02 \mathrm{~nm}, 1.46 \pm 0.05 \mathrm{~nm}$, and $1.34 \pm 0.02 \mathrm{~nm}$, respectively, and remained almost unchanged at $37{ }^{\circ} \mathrm{C}$ (Table 1); the C5L tag increased the $R_{\mathrm{h}}$ to $2.11 \pm 0.14 \mathrm{~nm}$, and the C5I tag increased the $R_{\mathrm{h}}$ to $3.12 \pm 0.06 \mathrm{~nm}$ at $25^{\circ} \mathrm{C}$ (Figure $2 \mathrm{a}$ and Table 1). All three 5 Ile-tagged variants (N5I, C5I, and ssC5I) formed aggregates with similar hydrodynamic radii $\left(R_{\mathrm{h}} \sim 3.12 \mathrm{~nm}\right.$ to $\left.\sim 3.97 \mathrm{~nm}\right)$ at $37{ }^{\circ} \mathrm{C}$ (Table 1 and Supplementary Figure $\mathrm{S} 1 \mathrm{~b})$. Importantly, the sizes of the sub-visible aggregates analyzed just before immunization remained almost constant from dose to dose (Figure 2b). These observations clearly suggested that the increased hydrodynamic radii observed for the C5I-tagged BPTI originated from the SCP-tag attachment. The overall order of hydrodynamic radii at $37{ }^{\circ} \mathrm{C}$ was thus BPTI19A $<$ C5A/C5V $<$ C5L $<$ N5I $<$ C5I/ssC5I (Table 1 and Supplementary Figure S1b) fully corroborating our previous observations ${ }^{35}$. Similarly, static light scattering (SLS) showed that the scattering intensities increased with increasing hydrophobicity ${ }^{37}$ of the SCP-tags (Figure 2c and Supplementary Figure S1c) indicating that the attachment of a hydrophobic Ile-tag produced aggregates which are in agreement with DLS observations (Supplementary Figure S1d).

In addition to DLS and SLS, the sizes of the aggregates were determined by sedimentation velocity experiment using analytical ultra centrifugation (AUC). The results showed that at 33 ${ }^{\circ} \mathrm{C}$ BPTI-19A and C5A had homogenous average molecular weights of $\sim 6 \mathrm{kDa}$ indicating that they are monomers. C5V was also nearly homogenous with an average molecular weight of $\sim 8$ kDa (Figure 2d and Table 2). However, C5L and N5I contained an oligomeric populations. In particular, ssC5I, which had the largest $R_{\mathrm{h}}$ showed various species of aggregates existed in the solution, and the average molecular weight of the aggregates was estimated to be $\sim 230 \mathrm{kDa}$. 
Altogether, AUC and the SLS results were in good agreement with the DLS observations where C5I tag induced the highest oligomeric size, intensity and molecular weight.

\section{Effects of SCP-tags on the structures of BPTI variants}

The impacts of SCP-tags on the conformational stability of BPTI-19A were investigated using Tyr-fluorescence and CD under conditions identical to those used for DLS $(0.3 \mathrm{mg} / \mathrm{mL}$ in PBS, $\mathrm{pH}$ 7.4). Fluorescence spectra showed that all BPTI variants maintained native conformation except $\mathrm{C} 5 \mathrm{I} / \mathrm{ssC} 5 \mathrm{I}$ which quenched the tyrosine fluorescence at 25 and $37{ }^{\circ} \mathrm{C}$ (Figure 3a and 3b, Supplementary Figure S2a). Additionally, the fluorescence of C5L showed a marginal reduction when the temperature was increased to $37^{\circ} \mathrm{C}$. We can interpret this quenching as a partial denaturation, where the tyrosine residues are becoming exposed to water molecules and their mobility increase ${ }^{\mathbf{3 8}}$ Note that, all the variants showed reversibility when the temperature was cooled back to $4{ }^{\circ} \mathrm{C}$ (Supplementary Figure S2b-S2c) which corroborated with our previous results ${ }^{35}$.

To understand the effect of secondary structural changes on the conformation of BPTI variants $\mathrm{CD}$ measurements were carried out and the supernatants' spectra at 25 and $37^{\circ} \mathrm{C}$ revealed that none of the SCP-tags affected the native-like secondary structure contents, except C5I/ssC5I (Figure 3c and 3d, Supplementary Figure S2d-S2j) which was slightly denatured at 25 and 37 ${ }^{\circ} \mathrm{C}$ (C5L was partially denatured at $37{ }^{\circ} \mathrm{C}$ but not at $25{ }^{\circ} \mathrm{C}$ in line with the above tyrosine fluorescence results). This partial denaturation occurs because of the hydrophobic environment created by the hydrophobic tags upon BPTI-19A's oligomerization and we related this to a multi-molecular reversed hydrophobic effect ${ }^{39}$. The association was reversible when CD spectra were measured at low concentration or temperature, and the tagged BPTI variants are fully folded as previously assessed by Trypsin inhibition assay performed at $280 \mathrm{nM}{ }^{35}$. Thus, the present results confirm the reversible association of all SCP-tagged BPTI-19A variants, which retain a native-like structure in the monomeric state, and they suggest that the SCP-tags did not affect the native biophysical properties of BPTI-19A, except producing temperaturedependent nanometer-size sub-visible aggregates under inoculation condition used in the present study. 


\section{Effects of nanometer size aggregates on protein immunogenicity}

We investigated the sizes of SCP-tag induced sub-visible aggregates on the immunogenicity of BPTI-19A in Jcl: ICR mice by ELISA. Both in the presence and absence of adjuvant, the untagged BPTI-19A with $R_{\mathrm{h}} \sim 1.34 \mathrm{~nm}$ was essentially non-immunogenic (Supplementary Figure S3a), as expected for a small protein. Similarly, no immune response was observed during the first two doses for any of the variants even in the presence of adjuvant. However, after the third dose, the antibody titers of the tagged BPTIs started to increase (Figure 4a), and after the final dose, the heart-bleed sera of C5I/ssC5I exhibited the highest absorbance at 492 nm (Figure 4b). C5A and C5V having $R_{\mathrm{h}}$ close to untagged 19A $\left(R_{\mathrm{h}} \sim 1.5 \mathrm{~nm}\right)$ and C5L which was slightly larger $\left(R_{\mathrm{h}} \sim 2.3 \mathrm{~nm}\right)$ than that of the untagged BPTI-19A, increased the immunogenicity by $15-23$ fold. Upon a further increase of the hydrodynamic radius to $\sim 3.7 \mathrm{~nm}$ by attaching the 5-Ile tags, the anti-BPTI-19A titers increased over 55 fold (Table 3 and Supplementary Figure S3b), in line with their aggregate sizes and SLS intensities (Figure 4c and Supplementary Figure S3c). Notably, ssC5I $\left(R_{\mathrm{h}} \sim 3.96 \mathrm{~nm}\right)$ also enhanced the titer by 66 fold indicating that the increase in antibody titers observed with 5-residue Ile-tag was independent of the type of residues (Gly or Ser) used as a spacer. On the other hand, the Nterminus-tagged BPTI-N5I increased the IgG titer only 22 fold which was almost one-third of the average titer observed for C5I (N5I also formed smaller aggregates than C5I, $R_{\mathrm{h}} \sim 3.13 \mathrm{~nm}$ ). Noteworthy, the antibody responses were directed against the BPTI-19A and not against the tag sequence as demonstrated by the ELISA signals, obtained with plates coated with BPTI19A without a tag or BPTI-19A with their respective tags, self-tags. (Supplementary Figure S3d). Immunization experiments in the absence of adjuvant showed similar results, in which C5I increased the antibody titer of BPTI-19A by 90 to 222 fold (Figure 4d and Table 3). Thus, the effect of the tags was comparable, and furthermore cumulative, to that of the traditional Freund's adjuvant (Supplementary Figure S3e), confirming the strong potential of SCP-tag as a target-specific adjuvant.

\section{Immune response maintenance and immunogenic memory}

Finally, we assessed the long-term maintenance of the immune responses generated by the untagged BPTI-19A and BPTI-C5I. Mice were injected with three consecutive doses at 3-week intervals, kept untreated for 70 days (10 weeks), but during this period the IgG level was measured weekly through tail-bleeding. Anti-BPTI-19A IgG levels, as measured by ELISA, 
remained high over 8 weeks for the mice injected with C5I, before declining. Furthermore, BPTI-19A memory was generated by the aggregates. Seventy days after the $3^{\text {rd }}$ dose, the $4^{\text {th }}$ dose of C5I boosted the IgG titers by 2300-3600 fold, whereas the response of mice immunized with the untagged BPTI-19A remained almost nil throughout the entire immunization scheme (Figure 4e). Altogether, these observations indicated that the immune response was longlasting and further that B-cell immune memory was established.

\section{SCP-tags for biophysical and immunological study}

A link between protein aggregation and immunogenicity has been suspected for a long time, however, without reaching a strong consensus. The lack of consistency was often blamed on to the inherent disparity arising from in vivo experiments, but it appears that in many reports, the sample condition might not have been sufficiently controlled or even measured. From this viewpoint, the nanometer-size sub-visible aggregates produced by attaching hydrophobic SCPtags, are well controlled and avoid the random events encountered by aggregates produced by physical or chemical stresses. Furthermore, we carefully assessed the aggregates' size and its stability upon temperature, $\mathrm{pH}$, protein concentration and type of tags. We further performed a near "real-time" monitoring of the hydrodynamic radius of the aggregates ${ }^{\mathbf{4 0}}$ just before each round of inoculation. We believe that such monitoring of the aggregates' size is essential as these aggregates may grow and dissociate upon small variation of external factors. Consequently, SCP-tags combined with our "real-time" monitoring protocol could provide a new tool for producing aggregates in a stable manner and analyzing the effect of aggregation on immunogenicity, from a biophysical viewpoint.

\section{Conclusion}

The effects of sub-visible aggregates of a few nanometers dimension on a protein's immunogenicity have mostly been ignored due to technical challenges in isolating, characterizing, and monitoring them. To the best of our knowledge, this is the first report showing as directly as currently possible, that aggregates as small as a few nanometers $\left(R_{\mathrm{h}}<5\right.$ $\mathrm{nm}$ ) can convert a non-immunogenic protein into a highly immunogenic one. Aggregates smaller than $0.2 \mu \mathrm{m}(200 \mathrm{~nm})$ cannot be removed by filtering using standard filters or centrifugation, and our study thus emphasizes the usefulness of monitoring the presence of 
small oligomers (or sub-visible aggregates) during the storage and formulation of therapeutic proteins. Finally, the present results show that the SCP-tags can be used to control the aggregates' size in a systematic and stable manner, and as such, they can contribute to a better understanding of the mechanisms underlying aggregation-triggered immunogenicity of proteins. 


\section{Materials and Methods}

\section{Construction of SCP-tagged BPTI variants (C5A, C5V, C5L, C5I/ssC5I and N5I)}

All BPTI variants were constructed with a pMMHa vector ${ }^{35}$. DNA sequences encoding two Gly/Ser residues (serving as a spacer), and the SCP-tags were added to the C-terminus of the template BPTI-19A [a BPTI containing 19 alanines out of its 58 residues ${ }^{\mathbf{3 1}}$ sequence using QuikChange site-directed mutagenesis (Stratagene, USA). The plasmid sequences were confirmed by DNA sequencing (ABI PRISM 3130xl Genetic Analyzer, USA). BPTI variants were named according to the number and type of amino acids added to the C-terminus of BPTI19A (Figure 1). For example, C5I stands for five Isoleucine residues added after two glycines as a spacer at the C-terminus of BPTI-19A. Similarly, N5I indicates a mutant with five isoleucine added at the N-terminus of BPTI with two glycines as a spacer.

\section{Protein expression, purification and sample preparation}

All BPTI variants were expressed in Escherichia coli BL21 (DE3) pLysS cell lines at $37^{\circ} \mathrm{C}$ and purified by pI precipitation, followed by reverse phase HPLC as per our previous protocol 35. Protein identities were confirmed by MALDI-TOF mass spectrometry (AB SCIEX TOF/TOF TM 5800, USA) and the purified proteins were preserved at $-30{ }^{\circ} \mathrm{C}$ as lyophilized powder. While preparing samples, the lyophilized protein powders were first dissolved at $1 \mathrm{mg} / \mathrm{mL}$ in MilliQ water (Millipore A10 ultra-pure water purifier, EMD Millipore, Germany) as protein stocks, and the final working sample was prepared in phosphate buffered saline (PBS, pH 7.4-filtered by $0.2 \mu \mathrm{m}$ Minisart filters) at $0.3 \mathrm{mg} / \mathrm{mL}$ concentration as determined by the extinction coefficient $\left(\mathrm{A}_{280}\right)$ using Nanodrop (Nanodrop-2000, Thermo Fisher Scientific, USA). Stock samples were centrifuged at $20,000 x g$ for 20 minutes at $4{ }^{\circ} \mathrm{C}$. Working samples were kept at $25{ }^{\circ} \mathrm{C}$ for 20 minutes and centrifuged just before measurements to remove aggregates, if there was any.

Analysis of sub-visible protein aggregates by dynamic light scattering (DLS), static light scattering (SLS) and analytical ultra-centrifugation (AUC) 
The sub-visible aggregates' sizes were measured by preparing the BPTI variants in PBS at 0.3 $\mathrm{mg} / \mathrm{mL}$. As mentioned earlier, samples were left still for 20 minutes at $25{ }^{\circ} \mathrm{C}$, centrifuged $\left(20,000 \mathrm{xg}\right.$ for 20 minutes at $\left.25^{\circ} \mathrm{C}\right)$, and the supernatants were used for DLS measurements (Malvern Zetasizer Nano-S System, UK). The $R_{\mathrm{h}}$ was measured at 25 and $37^{\circ} \mathrm{C}$ and calculated as the average of three independent readings from the number distributions using the StokesEinstein equation ${ }^{41}$. The presence of sub-visible aggregates was also monitored using static light scattering (SLS). The intensity of the supernatants was monitored at $600 \mathrm{~nm}$ wavelength at 25 and $37^{\circ} \mathrm{C}$ with an FP-8500 spectrofluorometer (JASCO, Japan) using a cuvette with a 3 mm optical path length. Each measurement was accumulated three times, and the values were averaged.

AUC's samples were prepared in the same way as the injected samples (or DLS) at a protein concentration of $0.3 \mathrm{mg} / \mathrm{mL}$. Sedimentation velocity experiments were carried out using an Optima XL-A analytical ultracentrifuge (Beckman-Coulter, USA) with a four-hole An60Ti rotor at 25 and $33{ }^{\circ} \mathrm{C}$. Before centrifugation, the samples were dialyzed overnight against buffer solution with PBS pH 7.4. The solvent density, viscosity and protein partial specific volumes were calculated using SEDNTERP software ${ }^{\mathbf{4 2}}$. Each sample was then transferred into a cell with a two-channel centerpiece. Data were obtained at 50,000 rpm. Absorbance at $280 \mathrm{~nm}$ scans were collected at 10 minutes intervals during sedimentation. Data analysis was performed by continuous distribution $c(\mathrm{~s})$ analysis module in the SEDFIT program ${ }^{43}$. Frictional ratio (f/fo) was allowed to float during fitting. The $c$ (s) distribution was converted into a molar mass distribution c $(\mathrm{M})$.

\section{Structural analysis of BPTI variants by Tyr Fluorescence and Circular Dichroism (CD) spectroscopy}

Tertiary and secondary structures of all BPTI variants were monitored through Tyrfluorescence and CD spectroscopy using an FP-8500 spectrofluorometer and a JASCO J820 CD spectropolarimeter (JASCO, Japan), respectively. Tyr-fluorescence ( $\lambda_{\mathrm{ex}} 275 \mathrm{~nm}$ ) of all BPTI variants was measured at various temperatures such as $4-25-37^{\circ} \mathrm{C}$, and the reversibility was checked by cooling the sample to $4{ }^{\circ} \mathrm{C}$ (re- $4{ }^{\circ} \mathrm{C}$ ). A quartz cuvette with $3 \mathrm{~mm}$ optical path length was used to carry out the fluorescence measurements, and $\lambda_{\mathrm{em}}$ was recorded between the wavelengths of 280-450 nm. Similarly, the CD spectra of proteins' supernatants were recorded in the wavelength range of 200-260 nm using a 1mm optical path length cuvette at 25 and 37 
${ }^{\circ} \mathrm{C}$ and cooling them back to $25^{\circ} \mathrm{C}$ (re- $25^{\circ} \mathrm{C}$ ). In both experiments, the concentrations of the protein samples were maintained as same as the DLS or SLS measurement conditions $(0.3$ $\mathrm{mg} / \mathrm{mL}$ in PBS pH 7.4.)

\section{Immunization experiments}

The inoculation samples were prepared by dissolving the lyophilized powder in MilliQ water at a concentration of $1 \mathrm{mg} / \mathrm{mL}$. The samples were aliquoted into 10 single-use samples and kept at $-30{ }^{\circ} \mathrm{C}$ until use. Prior to each inoculation, the samples were slowly thawed at room temperature, reconstituted into the final buffer (PBS) at a concentration of $0.3 \mathrm{mg} / \mathrm{ml}$, incubated for 20 minutes at $25^{\circ} \mathrm{C}$, centrifuged, and the aggregates' sizes were monitored by measuring the $R_{\mathrm{h}}$ at 25 and $37^{\circ} \mathrm{C}$ by DLS (see above for measurement details).

Four-week-old female mice (Jcl: ICR, CLEA, Japan) were injected with the BPTI variants. All of the experiments were performed in compliance with TUAT's and Japanese governmental regulations on animal experimentation. The mice were accommodated on sterilized wood bedding at an ambient temperature maintained at $22 \pm 0.5^{\circ} \mathrm{C}$ and relative humidity around $47 \pm 8$ $\%$ with a natural half-day light-dark cycle. Subcutaneous (SC) injection was carried out with the untagged and SCP-tagged BPTIs at $30 \mu \mathrm{g} / 100 \mu \mathrm{L} /$ dose without adjuvant. Additionally, for injection with adjuvant (WAKO, Japan), the first dose was given subcutaneously with Freund's incomplete adjuvant (protein: adjuvant $=1: 1$ ), and doses 2-4 with Freund's complete adjuvant were given intraperitoneally (IP) at weekly intervals. In all experiments, the quantity of injected protein was $30 \mu \mathrm{g}$. Control mice were injected with PBS in the presence or absence of adjuvant.

Three days after each inoculation, $\sim 20 \mu \mathrm{L}$ of tail-bleed samples were collected and used for measuring the level of anti-BPTI IgG antibodies by using ELISA (see the next section). After the final dose, heart-bleed samples were collected when mice were sacrificed through spinalcord dislocation. These heart-bleed serum samples were preserved in 1:4 dilutions in PBS supplemented with $20 \%$ glycerol and stored at $-30{ }^{\circ} \mathrm{C}$.

\section{Detection of anti-BPTI responses by ELISA}


Anti-BPTI immune response was measured by ELISA using 96-well microtiter plates (TPP micro-titer plates, Japan). HPLC purified untagged BPTI-19A $(2.5 \mu \mathrm{g} / \mathrm{mL}$ in PBS) was used for overnight coating of the plate at $25^{\circ} \mathrm{C}$. Unbound proteins were washed out with PBS, and the plates were blocked with $1 \%$ BSA in PBS for 45 minutes at $37{ }^{\circ} \mathrm{C}$, followed by washing with PBS once.

Anti-BPTI sera were applied at an initial dilution of 1:50 for the tail-bleed samples, and 1:300 for the heart-bleed samples, followed by 3 -fold serial dilution in subsequent wells containing $0.1 \%$ BSA-PBS. Plates were then incubated at $37{ }^{\circ} \mathrm{C}$ for 2 hours. A positive control was used in all ELISA plates. After washing three times with PBS-0.05\% Tween-20, 100 $\mu 1 /$ well of antimouse IgG HRP conjugate (Thermo Fisher Scientific, USA; at 1:3000 dilution in 0.1\% BSAPBS-Tween-20) was added and incubated at $37^{\circ} \mathrm{C}$ for 90 minutes. Finally, unbound conjugates were removed by thoroughly washing three times with PBS-0.05\% Tween-20. Coloring was performed by adding the O-phenyl Di-amine (OPD) substrate and incubating for 20 minutes (100 $\mu \mathrm{l} /$ well; OPD $0.4 \mathrm{mg} / \mathrm{ml}$ supplemented with $4 \mathrm{mM}$ hydrogen peroxide). Color intensities were measured at $492 \mathrm{~nm}$ using a microplate reader (SH-9000 Lab, Hitachi High-Tech Science, Japan) immediately after stopping the reaction with $1 \mathrm{~N}$ sulfuric acid $(50 \mu \mathrm{L} /$ well $)$.

\section{Acknowledgements}

We thank the members of the Kuroda's laboratory for technical help and discussion. We are grateful to Ms. Patricia S. McGahan for English proofreading and Profs Tsuyoshi Tanaka and Tomoko Yoshino and for the use of the Zetasizer.

\section{Author Contribution}

Y.K., M.M.I., N.R. designed the project, and wrote the manuscript. N.R., S.U., M.M.I., and S.M. performed the experiments and analyzed and compiled the data. All authors read and approved the manuscript. 


\section{Conflict of interest}

No conflict of interests

\section{Funding}

This study was supported by a JSPS Grant-in-Aid for Scientific Research (KAKENHI15H04359) to YK, a JSPS post-doctoral and a JSPS invitation fellowship (FY 2015), a GARE (MOE, Bangladesh) funding to MMI, the TUAT's Institute of Global Innovation Research, and a Japanese government (Monbukagakusho: MEXT) PhD scholarship to NR.

\section{Competing interests}

The authors declare no competing interests

\section{Data Sharing}

All data are given in the manuscript and the supplementary data.

\section{Notes}

The SCP-tag sequences are covered by a Japanese patent 5273438 and an international (PCT) patent application PCT/JP2018/029395. 


\section{Figure legends}

Figure 1. Sequences and structure of SCP-tagged BPTI. The untagged BPTI-19A contains 58 amino acid residues. C5A, C5V, C5L, and C5I variants were designed by attaching their respective tags at the $\mathrm{C}$-terminus (site-directed mutagenesis) except $\mathrm{N} 5 \mathrm{I}$ having the tag at the $\mathrm{N}$-terminus. Two glycine or serine residues served as a spacer between the host protein and the SCP-tags.

Figure 2. Influence of SCP-tags on sub-visible aggregates' sizes measured by DLS and SLS and AUC. a) DLS spectra of the size distribution Number $(\%)$ at $25^{\circ} \mathrm{C}$. b) Hydrodynamic radii of SCP-tagged BPTI variants measured just before immunization from dose- 1 to dose- 4 at 25 (white bars) and $37{ }^{\circ} \mathrm{C}$ (grey bars) respectively. The $R_{\mathrm{h}}$ were computed from DLS's number spectra. c) Aggregation intensities of SCP-tagged BPTI variants at $25^{\circ} \mathrm{C}$ measured by SLS. d) Increase in the average molecular weights at $33{ }^{\circ} \mathrm{C}$ (black line) with respect to the hydrodynamic radii (bars) of SCP-tagged BPTI variants at $37{ }^{\circ} \mathrm{C}$ as measured by AUC. Proteins were formulated at $0.3 \mathrm{mg} / \mathrm{mL}$ concentrations in PBS pH 7.4 for all measurements. Values are shown as the average of three independent measurements and three accumulations for DLS and SLS, respectively. Line symbols are explained within the panels.

Figure 3. Spectroscopic analysis of untagged BPTI-19A and its SCP-tagged variants by fluorescence and CD measurements. Tyr-fluorescence spectra of 19A, C5A, C5V, C5L and $\mathrm{C} 5 \mathrm{I} / \mathrm{ssC} 5 \mathrm{I}$ at a) $25^{\circ} \mathrm{C}$ and b) $37^{\circ} \mathrm{C}$. CD spectra of all BPTI variants at c) $25^{\circ} \mathrm{C}$ and d) $37{ }^{\circ} \mathrm{C}$. All protein samples were formulated in PBS, $\mathrm{pH} 7.4$, at a concentration of $0.3 \mathrm{mg} / \mathrm{mL}$. Three accumulations were taken for each measurement. Line symbols are explained within the panels.

Figure 4. Antibody responses against untagged BPTI-19A and its SCP-tag induced subvisible aggregates assayed by ELISA. Immunization in the presence of adjuvant is indicated by '+', whereas '-' stands for immunization in the absence of adjuvant. a) Dosewise antibody titers of untagged BPTI-19A and SCP-tagged BPTI variants (C5A, C5V, C5L, N5I, and $\mathrm{C} 5 \mathrm{I} / \mathrm{ssC} 5 \mathrm{I})$ in the presence of adjuvant using tail-bleed serum samples. b) OD at $492 \mathrm{~nm}$ of anti-BPTI-19A, C5A, C5V, C5L, N5I, and C5I/ssC5I sera (with adjuvant) measured by ELISA of the respective heart bleed samples. c) Increase in antibody titers (black line) with respect to the hydrodynamic radii (bars) of SCP-tagged BPTI variants at $37{ }^{\circ} \mathrm{C}$. d) Antibody titers produced against untagged-19A and C5I/ssC5I-tagged BPTIs in the absence of adjuvant. '*' shows the results for individual mice. e) Long term antibody titers against BPTI-19A and BPTI- 
$\mathrm{C} 5 \mathrm{I} / \mathrm{ssC} 5 \mathrm{I}$ in the absence of adjuvant. ' $\mathrm{D}$ ' indicates the number of days at which tail bleeding was performed counting from the first inoculation. All doses were formulated at $0.3 \mathrm{mg} / \mathrm{mL}$ concentrations in PBS throughout the immunization scheme. Line symbols are explained within the panels. 


\begin{tabular}{|c|c|c|c|}
\hline \multirow{2}{*}{ Mutant Identities } & \multicolumn{3}{|c|}{ Hydrodynamic Radius $(\boldsymbol{R} \mathbf{h}, \mathbf{n m})$ in PBS } \\
\cline { 2 - 4 } & $25^{\circ} \mathrm{C}$ & $37^{\circ} \mathrm{C}$ & re-25 ${ }^{\circ} \mathrm{C}$ \\
\hline BPTI-19A & $1.33 \pm 0.02$ & $1.34 \pm 0.02$ & $1.26 \pm 0.016$ \\
\hline BPTI-C5A & $1.46 \pm 0.05$ & $1.53 \pm 0.06$ & $1.43 \pm 0.06$ \\
\hline BPTI-C5V & $1.34 \pm 0.02$ & $1.39 \pm 0.06$ & $1.31 \pm 0.06$ \\
\hline BPTI-C5L & $2.11 \pm 0.14$ & $2.34 \pm 0.13$ & $2.19 \pm 0.26$ \\
\hline BPTI-N5I & $1.49 \pm 0.30$ & $3.13 \pm 0.23$ & $2.85 \pm 0.44$ \\
\hline BPTI-C5I & $3.12 \pm 0.06$ & $3.71 \pm 0.13$ & $3.23 \pm 0.10$ \\
\hline BPTI-ssC5I & $3.47 \pm 0.09$ & $3.97 \pm 0.22$ & $3.42 \pm 0.08$ \\
\hline
\end{tabular}

Table 1: Hydrodynamic radius of BPTI-19A and its SCP-tagged variants. Proteins were formulated at $0.3 \mathrm{mg} / \mathrm{mL}$ concentrations in PBS. DLS measurements were carried out just before immunization at $25{ }^{\circ} \mathrm{C}$ followed by $37^{\circ} \mathrm{C}$ and again at $25^{\circ} \mathrm{C}\left(\right.$ re $\left.-25^{\circ} \mathrm{C}\right)$. The values are the average of three independent measurements where \pm sign indicates a standard deviation $(\mathrm{SD}) . R_{\mathrm{h}}$ was calculated from the number distributions using the Stokes-Einstein equation. 


\begin{tabular}{|c|c|c|}
\hline \multirow{2}{*}{ Mutant } & Molecular weights (kDa) & Population (\%) \\
\cline { 2 - 3 } & $\mathbf{3 3}^{\circ} \mathbf{C}$ & $\mathbf{3 3}^{\circ} \mathbf{C}$ \\
\hline BPTI-19A & $6.1 \mathrm{kDa}$ & $89.66 \%$ \\
\hline BPTI-C5A & $6.3 \mathrm{kDa}$ & $92.13 \%$ \\
\hline BPTI-C5V & $8.3 \mathrm{kDa}$ & $74.59 \%$ \\
\hline BPTI-C5L & $9.7 \mathrm{kDa}$ & $48.37 \%$ \\
\hline BPTI-N5I & $9.6 \mathrm{kDa}$ & $56.98 \%$ \\
\hline BPTI-C5I & Large* & $*$ \\
\hline
\end{tabular}

Table 2: Sedimentation velocity experiment with BPTI-19A and its SCP-tagged variants using AUC. AUC experiments were carried out with a protein concentration of $0.3 \mathrm{mg} / \mathrm{mL}$ at $33{ }^{\circ} \mathrm{C}$. The $\mathrm{c}(\mathrm{s})$ distribution was converted into a molar mass distribution $\mathrm{c}(\mathrm{M})$ and thus the average molecular weights of different BPTI variants were calculated. C5I could not be measured as it contained various populations (indicated by '*' '). 


\begin{tabular}{|c|c|c|c|c|}
\hline $\begin{array}{c}\text { Dose } \\
\text { formulation }\end{array}$ & Mutants & Tags & $\begin{array}{c}\text { Average IgG } \\
\text { Titers }^{1}\end{array}$ & Fold increased $^{2}$ \\
\hline \multirow{7}{*}{$\begin{array}{c}\text { With adjuvant } \\
(+)\end{array}$} & BPTI-19A & $x$ & 1171.9 & 1 \\
\hline & BPTI-C5A & $\mathrm{Gly}_{2} \mathrm{Ala}_{5}$ & 27280.3 & 23.3 \\
\hline & BPTI-C5V & $\mathrm{Gly}_{2} \mathrm{Val}_{5}$ & 18251.5 & 15.6 \\
\hline & BPTI-C5L & $\mathrm{Gly}_{2} \mathrm{Leu}_{5}$ & 18467.1 & 15.8 \\
\hline & BPTI-N5I & $\mathrm{Ile}_{5} \mathrm{Gly}_{2}$ & 26071.8 & 22.2 \\
\hline & BPTI-C5I & $\mathrm{Gly}_{2} \mathrm{Ile}_{5}$ & 64846.8 & 55.3 \\
\hline & BPTI-ssC5I & $\mathrm{Ser}_{2} \mathrm{Ile}_{5}$ & 77825.5 & 66.4 \\
\hline \multirow{3}{*}{$\begin{array}{l}\text { Without } \\
\text { adjuvant } \\
(-)\end{array}$} & BPTI-19A & $x$ & 82.1 & 1 \\
\hline & BPTI-C5I & $\mathrm{Gly}_{2} \mathrm{Ile}_{5}$ & 18267.1 & 222.5 \\
\hline & BPTI-ssC5I & $\mathrm{Ser}_{2} \mathrm{Ile}_{5}$ & 7417.4 & 90.4 \\
\hline
\end{tabular}

Table 3: Average IgG titer values and fold-increase of antibody titers for SCP-tagged BPTI variants with and without adjuvant. ${ }^{1}$ The titers were calculated using a power fitting model, and the values were averaged using the number of the mice (n) in respective groups [19A (+), n=4; C5A/V/L (+), n=3; N5I (+), n=4; C5I (+) n=3; ssC5I (+), n=4; 19A (-), n=3; C5I (-), n=3; ssC5I (-), n=3]. ${ }^{2}$ Fold-increase of antibody titers in the presence and absence of adjuvant were calculated with respect to the titer of BPTI-19A (+) and BPTI-19A (-), respectively. ' $x$ ' indicates the absence of tags. 


\section{Figure 1}

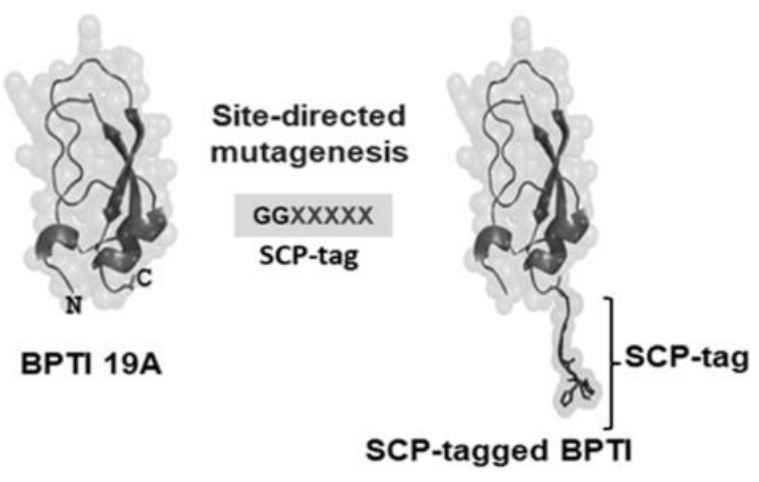

BPTI-19A $(5.98 \mathrm{kDa})$
BPTI-C5A $(6.45 \mathrm{kDa})$
BPTI-C5V $(6.59 \mathrm{kDa})$
BPTI-C5L $(6.66 \mathrm{kDa})$
BPTI-N5I $(6.66 \mathrm{kDa})$
BPTI-C5I $(6.66 \mathrm{kDa})$
BPTI-s5C5I $(6.72 \mathrm{kDa})$

RPAFCLEPPY AGPGKARIR YFYNAAAGAAQAFVYGGVRA KRNNFASAAD ALAACAAA

RPAFCLEPPY AGPGKARIR YFYNAAAGAAQAFVYGGVRA KRNNFASAAD ALAACAAAGGAAAAA RPAFCLEPPY AGPGKARIR YFYNAAAGAAQAFVYGGVRA KRNNFASAAD ALAACAAAGGVVVVY

RPAFCLEPPY AGPGKARIR YFYNAAAGAA QAFVYGGVRA KRNNFASAAD ALAACAAAGGLLLLL IIIIGGRPAFCLEPPYAGPGKARIR YFYNAAAGAAQAFVYGGVRAKRNNFASAAD ALAACAAA

RPAFCLEPPY AGPGKARIR YFYNAAAGAA QAFVYGGVRA KRNNFASAAD ALAACAAAGGIIII

RPAFCLEPPY AGPGKARIR YFYNAAAGAAQAFVYGGVRA KRNNFASAAD ALAACAAASSIIII

\section{Figure 2}

a)

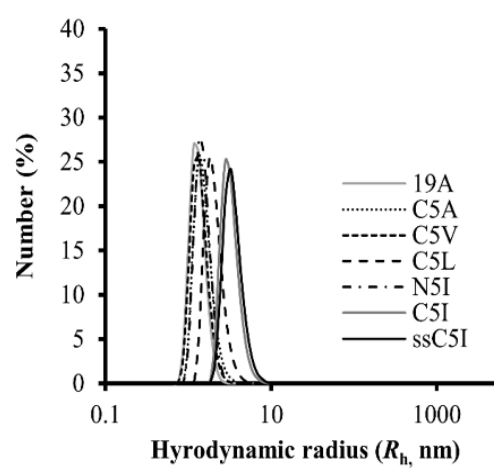

c)

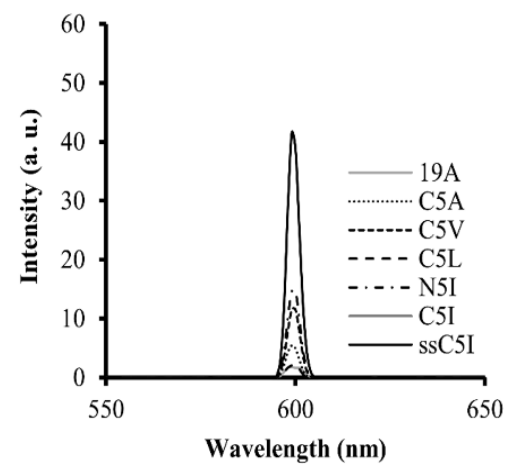

d)

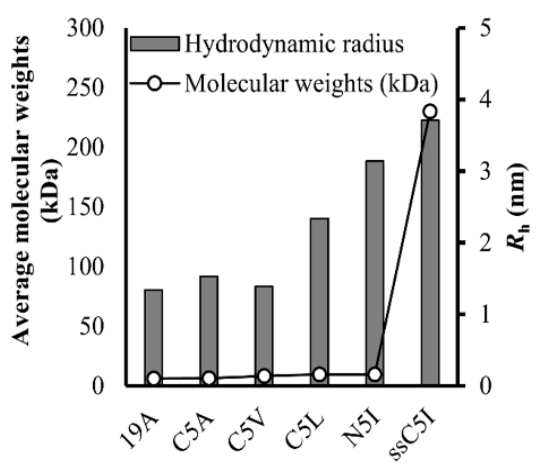

b)

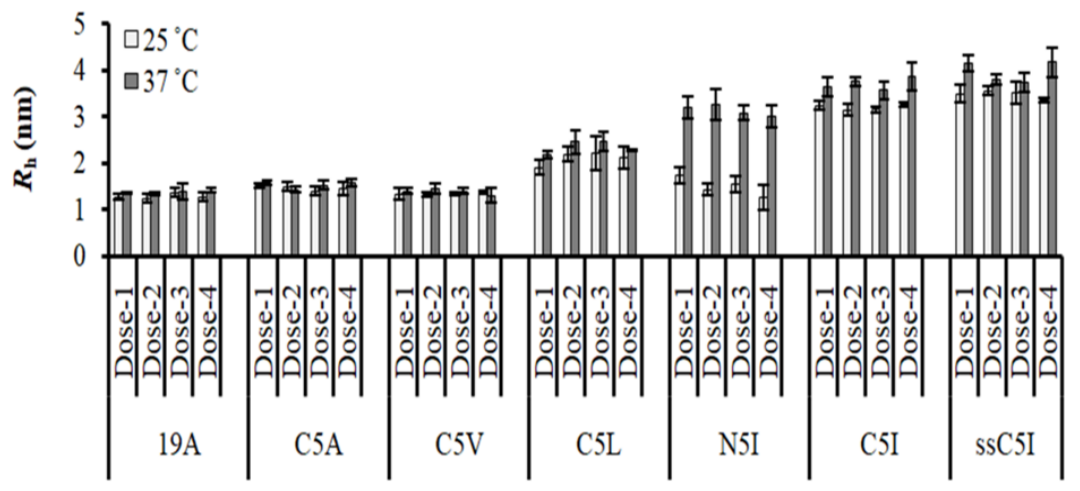




\section{Figure 3}

a)

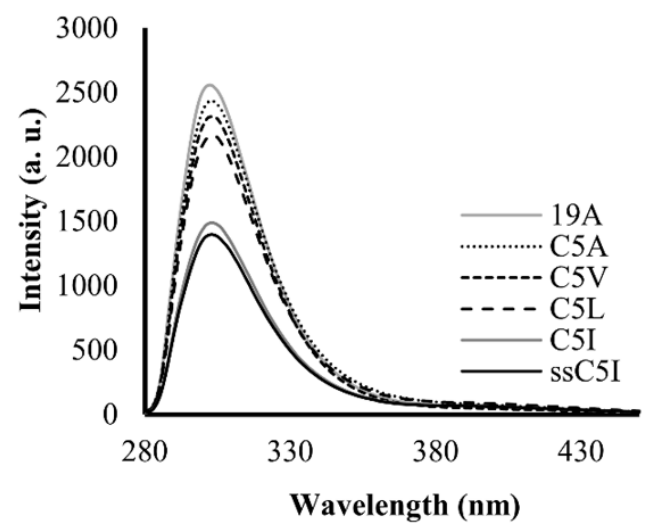

c)

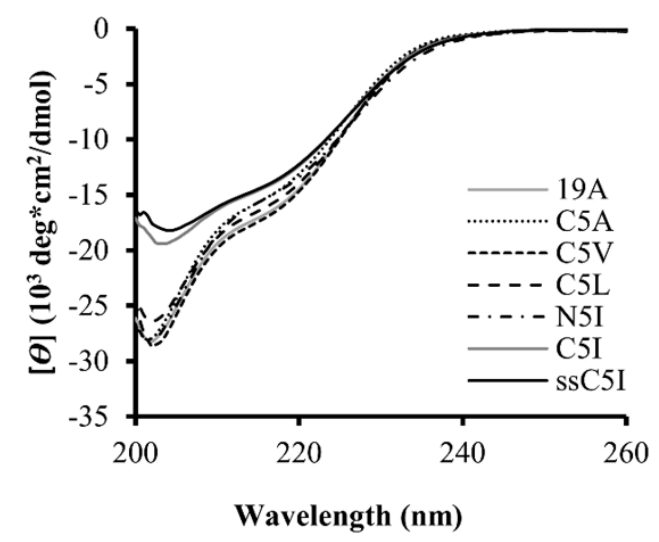

b)

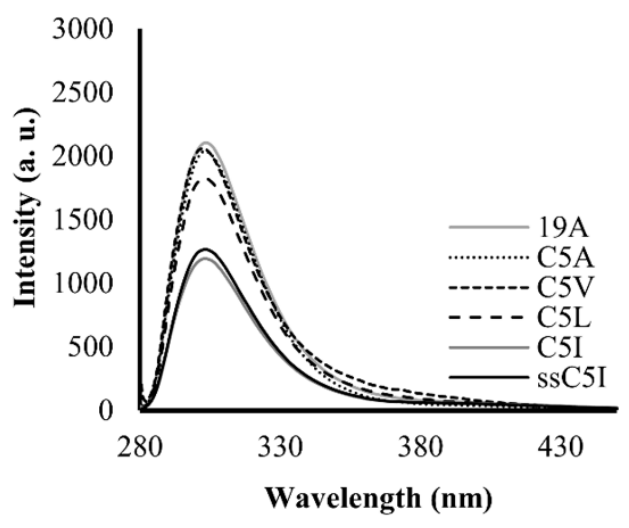

d)

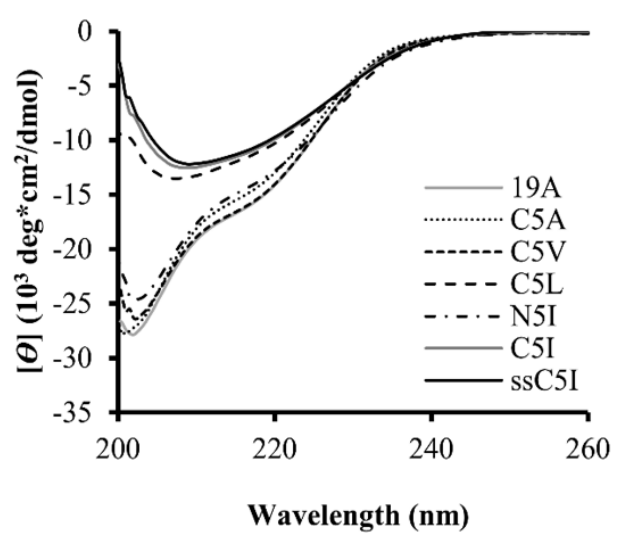




\section{Figure 4}

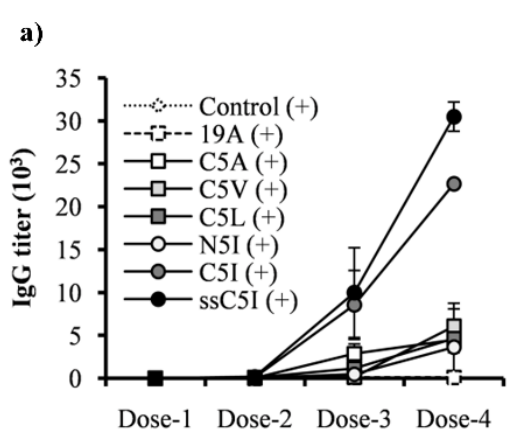

d)

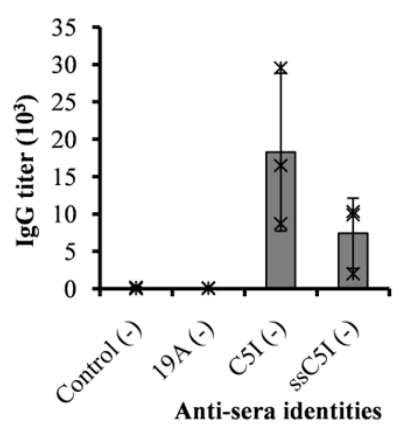

b)

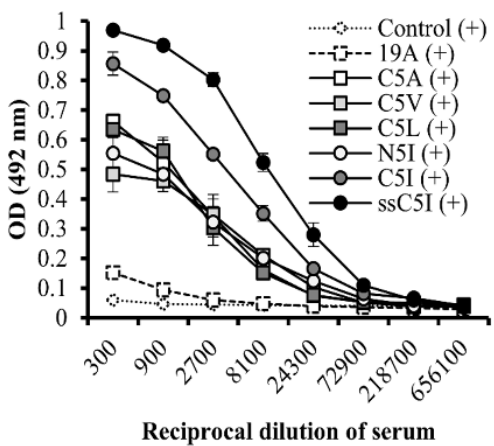

e)

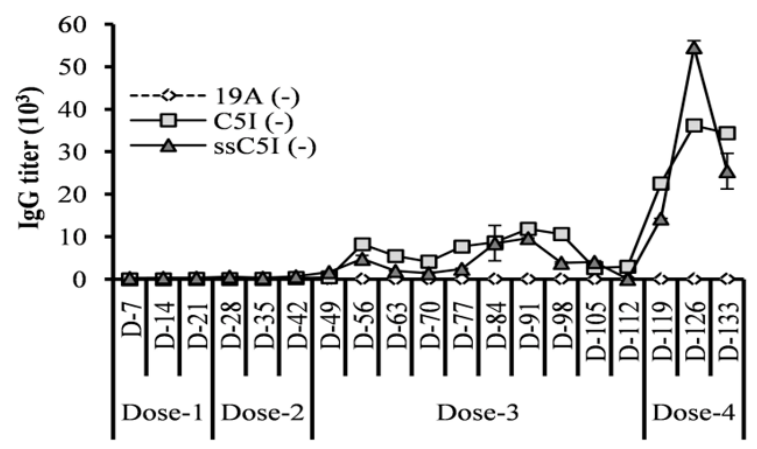

c)

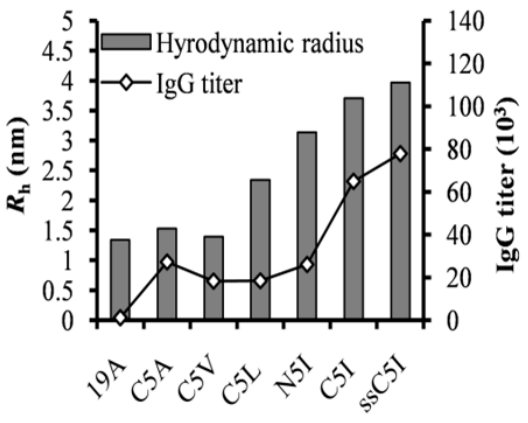




\section{References}

1 Ratanji, K. D., Derrick, J. P., Dearman, R. J. \& Kimber, I. Immunogenicity of therapeutic proteins: influence of aggregation. J Immunotoxicol 11, 99-109 (2014).

2 Salazar-Fontana, L. I. et al. Approaches to mitigate the unwanted immunogenicity of therapeutic proteins during drug development. Aaps $J$ 19, 377-385 (2017).

3 Jawa, V. et al. T-cell dependent immunogenicity of protein therapeutics: Preclinical assessment and mitigation. Clin Immunol 149, 534-555 (2013).

4 Purcell, R. T. \& Lockey, R. F. Immunologic responses to therapeutic biologic agents. J Investig Allergol Clin Immunol 18, 335-342 (2008).

5 Shankar, G. et al. Assessment and reporting of the clinical immunogenicity of therapeutic proteins and peptides-harmonized terminology and tactical recommendations. Aaps J 16, 658-673 (2014).

6 Boatz, J. C., Whitley, M. J., Li, M., Gronenborn, A. M. \& van der Wel, P. C. A. Cataract-associated P23T gammaD-crystallin retains a native-like fold in amorphouslooking aggregates formed at physiological pH. Nat Commun 8 (2017).

7 Mainz, A. et al. The chaperone alphaB-crystallin uses different interfaces to capture an amorphous and an amyloid client. Nat Struct Mol Biol 22, 898-905 (2015).

8 Uchiyama, S. Liquid formulation for antibody drugs. Biochim Biophys Acta 1844, 2041-2052 (2014).

9 Yoshimura, Y. et al. Distinguishing crystal-like amyloid fibrils and glass-like amorphous aggregates from their kinetics of formation. Proc Natl Acad Sci U S A 109, 14446-14451 (2012).

10 Freitag, A. J. et al. Investigation of the immunogenicity of different types of aggregates of a murine monoclonal antibody in mice. Pharm Res 32, 430-444 (2015).

11 Joubert, M. K. et al. Use of in vitro assays to assess immunogenicity risk of antibodybased biotherapeutics. PLoS One 11 (2016). 
12 Rombach-Riegraf, V. et al. Aggregation of human recombinant monoclonal antibodies influences the capacity of dendritic cells to stimulate adaptive T-cell responses in vitro. PLoS One 9 (2014).

13 Telikepalli, S. et al. Physical characterization and in vitro biological impact of highly aggregated antibodies separated into size-enriched populations by fluorescenceactivated cell sorting. J Pharm Sci 104, 1575-1591 (2015).

14 Joubert, M. K. et al. Highly aggregated antibody therapeutics can enhance the in vitro innate and late-stage T-cell immune responses. J Biol Chem 287, 25266-25279 (2012).

15 Ahmadi, M. et al. Small amounts of sub-visible aggregates enhance the immunogenic potential of monoclonal antibody therapeutics. Pharm Res 32, 1383-1394 (2015).

16 Eyes, T. J. et al. Identification of B cell epitopes enhanced by protein unfolding and aggregation. Mol Immunol 105, 181-189 (2019).

17 Ratanji, K. D. et al. Editor's Highlight: Subvisible aggregates of immunogenic proteins promote a th1-type response. Toxicol Sci 153, 258-270 (2016).

18 Filipe, V. et al. Immunogenicity of different stressed IgG monoclonal antibody formulations in immune tolerant transgenic mice. MAbs 4, 740-752 (2012).

19 Polumuri, S. K., Haile, L. A., Ireland, D. D. C. \& Verthelyi, D. Aggregates of IVIG or Avastin, but not HSA, modify the response to model innate immune response modulating impurities. Sci Rep 8, 018-29850 (2018).

20 Manning, M. C., Chou, D. K., Murphy, B. M., Payne, R. W. \& Katayama, D. S. Stability of protein pharmaceuticals: an update. Pharm Res 27, 544-575 (2010).

21 Moussa, E. M. et al. Immunogenicity of Therapeutic Protein Aggregates. J Pharm Sci 105, 417-430 (2016).

22 Ahmad, F. et al. Evaluation of aggregated Ag85B antigen for its biophysical properties, immunogenicity, and vaccination potential in a murine model of tuberculosis infection. Front Immunol 8 (2017). 
23 Ignatova, Z. \& Gierasch, L. M. Monitoring protein stability and aggregation in vivo by real-time fluorescent labeling. Proc Natl Acad Sci U S A 101, 523-528 (2004).

24 Purohit, V. S., Middaugh, C. R. \& Balasubramanian, S. V. Influence of aggregation on immunogenicity of recombinant human Factor VIII in hemophilia A mice. J Pharm Sci 95, 358-371 (2006).

25 Sauerborn, M. et al. Antibody response against Betaferon(R) in immune tolerant mice: involvement of marginal zone B-cells and CD4+ T-cells and apparent lack of immunological memory. J Clin Immunol 33, 255-263 (2013).

26 EMA. Guideline on immunogenicity assessment of therapeutic proteins $<$ https://www.ema.europa.eu/en/documents/scientific-guideline/guidelineimmunogenicity-assessment-therapeutic-proteins-revision-1_en.pdf > (2017).

s27 FDA. 2014. Guidance for industry immunogenicity assessment for therapeutic protein products. https://www.fda.gov/downloads/drugs/guidances/ucm338856.pdf. (2014).

28 Chennamsetty, N., Voynov, V., Kayser, V., Helk, B. \& Trout, B. L. Design of therapeutic proteins with enhanced stability. Proc Natl Acad Sci U S A 106, 1193711942 (2009).

29 Kalonia, C. et al. Effects of Protein Conformation, Apparent Solubility, and ProteinProtein Interactions on the Rates and Mechanisms of Aggregation for an IgG1Monoclonal Antibody. J Phys Chem B 120, $7062-7075$ (2016).

30 Jain, T. et al. Biophysical properties of the clinical-stage antibody landscape. Proc Natl Acad Sci U S A 114, 944-949 (2017).

31 Islam, M. M., Khan, M. A. \& Kuroda, Y. Analysis of amino acid contributions to protein solubility using short peptide tags fused to a simplified BPTI variant. Biochim Biophys Acta 10, 20 (2012).

32 Nautiyal, K., Kibria, M. G., Akazawa-Ogawa, Y., Hagihara, Y. \& Kuroda, Y. Design and assessment of an active anti-epidermal growth factor receptor (EGFR) single chain variable fragment ( $\mathrm{ScFv}$ ) with improved solubility. Biochem Biophys Res Commun 508, 1043-1049 (2019). 
33 Nautiyal, K. \& Kuroda, Y. A SEP tag enhances the expression, solubility and yield of recombinant TEV protease without altering its activity. N Biotechnol 42, 77-84 (2018).

34 Khan, M. A., Islam, M. M. \& Kuroda, Y. Analysis of protein aggregation kinetics using short amino acid peptide tags. Biochim Biophys Acta 10, 28 (2013).

35 Kabir, M. G., Islam, M. M. \& Kuroda, Y. Reversible association of proteins into subvisible amorphous aggregates using short solubility controlling peptide tags. Biochim Biophys Acta Proteins Proteom 2, 366-372 (2018).

36 Islam, M. M. et al. Analysis and control of protein crystallization using short peptide tags that change solubility without affecting structure, thermal stability, and function. Crystal Growth \& Design 15, 2703-2711, doi:10.1021/acs.cgd.5b00010 (2015).

37 Kyte, J. \& Doolittle, R. F. A simple method for displaying the hydropathic character of a protein. J Mol Biol 157, 105-132 (1982).

38 Bushueva, T. L., Busel, E. P. \& Burstein, E. A. Relationship of thermal quenching of protein fluorescence to intramolecular structural mobility. Biochim Biophys Acta 534, 141-152 (1978).

39 Pakula, A. A. \& Sauer, R. T. Reverse hydrophobic effects relieved by amino-acid substitutions at a protein surface. Nature 344, 363-364 (1990).

40 den Engelsman, J. et al. Strategies for the assessment of protein aggregates in pharmaceutical biotech product development. Pharm Res 28, 920-933 (2011).

41 Stetefeld, J., McKenna, S. A. \& Patel, T. R. Dynamic light scattering: a practical guide and applications in biomedical sciences. Biophys Rev 8, 409-427 (2016).

42 Laue TM, Shah BD, Ridgeway TM and Pelletier SL. Computer-aided interpretation of analytical sedimentation data for proteins. In: Harding SE, Rowe AJ, Horton JC, editors. Analytical Ultracentrifugation in Biochemistry and Polymer Science. Royal Society of Chemistry, Cambridge, U.K. (1992). 
43 Schuck, P., Perugini, M. A., Gonzales, N. R., Howlett, G. J. \& Schubert, D. Sizedistribution analysis of proteins by analytical ultracentrifugation: strategies and application to model systems. Biophys J 82, 1096-1111 (2002). 


\section{Supporting Information}

\section{Generation of "nanometer-size aggregates" using Solubility Controlling Peptide tags and their ability to increase a protein's immunogenicity in vivo}

Nafsoon Rahman, ${ }^{1}$ Mohammad Monirul Islam, ${ }^{2}$ Satoru Unzai, ${ }^{3}$ Shiho Miura ${ }^{1}$, Yutaka Kuroda ${ }^{*}$

${ }^{1}$ Department of Biotechnology and Life Sciences, Graduate School of Engineering, Tokyo University of Agriculture and Technology, 2-24-16 Nakamachi, Koganei-shi, Tokyo 184-8588, Japan. ${ }^{2}$ Department of Biochemistry and Molecular Biology, University of Chittagong, Chittagong-4331, Bangladesh. ${ }^{3}$ Department of Frontier Bioscience, Faculty of Bioscience and Applied Chemistry, Hosei University, 3-7-2 Kajino-cho, Koganei, Tokyo 184-8584, Japan. 


\section{Supplementary Information}

Figure S1: a) Effect of filtration and centrifugation on the concentrations of SCP tagged variants in at $0.3 \mathrm{mg} / \mathrm{ml}$ concentration $\mathrm{PBS} \mathrm{pH} 7.4 \mathrm{BF} / \mathrm{CF}$ means the concentration 'before filtration or centrifugation' and AF/AC means 'after filtration or centrifugation'. Three measurements were carried out and the values were averaged b) Hydrodynamic radius of untagged BPTI-19A and SCP tagged variants $\left(0.3 \mathrm{mg} / \mathrm{mL}\right.$ in PBS pH 7.4) at $37{ }^{\circ} \mathrm{C}$ in terms of their number (\%). Line symbols are explained within the panels c) Aggregation intensities of SCP tagged variants $(0.3 \mathrm{mg} / \mathrm{mL}$ in $\mathrm{PBS} \mathrm{pH} 7.4)$ at $37{ }^{\circ} \mathrm{C}$ measured by SLS. Three accumulations were carried out for each mutant. Line symbols are explained within the panels d) Increase in aggregation intensities of SCP tagged BPTI variants measured by SLS (0.3 $\mathrm{mg} / \mathrm{mL}$ in $\mathrm{PBS} \mathrm{pH} 7.4$ ) at $37^{\circ} \mathrm{C}$ with respect to their hydrodynamic radii.

Figure S2: Tyr-fluorescence of a) N5I at 4-25-37 and re- $4{ }^{\circ} \mathrm{C}$ (after cooling back from $37{ }^{\circ} \mathrm{C}$ ) b) Fluorescence spectra of 19A, C5A, C5V, C5L, C5I and ssC5I at b) $4{ }^{\circ} \mathrm{C}$ and c) re- $4{ }^{\circ} \mathrm{C}$ (after cooling back from $37^{\circ} \mathrm{C}$. CD analysis of the secondary structure contents of individual BPTI variants (d)-(j) was measured at 25,37 and re- $25^{\circ} \mathrm{C}$ (after cooling back from $37{ }^{\circ} \mathrm{C}$ ). Three accumulations were carried out for each mutant for both fluorescence and CD measurements with a protein concentration of $0.3 \mathrm{mg} / \mathrm{mL}$ in $\mathrm{PBS} \mathrm{pH} 7.4$.

Figure S3: a) Dose dependent OD values of control-sera (raised against PBS) and untagged BPTI-19A at $492 \mathrm{~nm}$ in the presence (+) and absence (-) of adjuvant b) Antibody titers of BPTItagged variants in the presence of adjuvant (+) after sacrificing the mice. Number of mice were indicated by '*' on the bar diagrams c) Increase in antibody titers of SCP tagged BPTI variants with respect to their aggregation intensities measured by SLS at $37{ }^{\circ} \mathrm{C} \mathrm{d}$ ) OD values of sera raised against C5A, C5V, C5L, N5I and C5I/ssC5I against coating antigen untagged BPTI-19A, self-tags and C5I e) OD values of heart-bleed sera of untagged BPTI-19A and BPTI-C5I/ssC5I at $492 \mathrm{~nm}$ in the presence (+) and absence (-) of adjuvant. 


\section{Figure S1}

a)

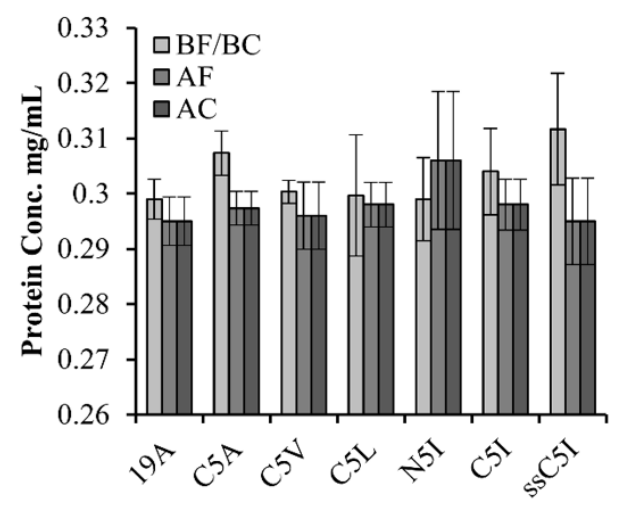

c)

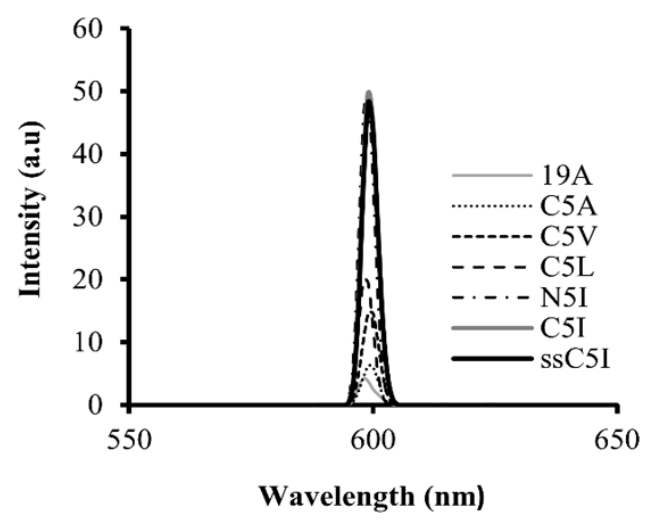

b)

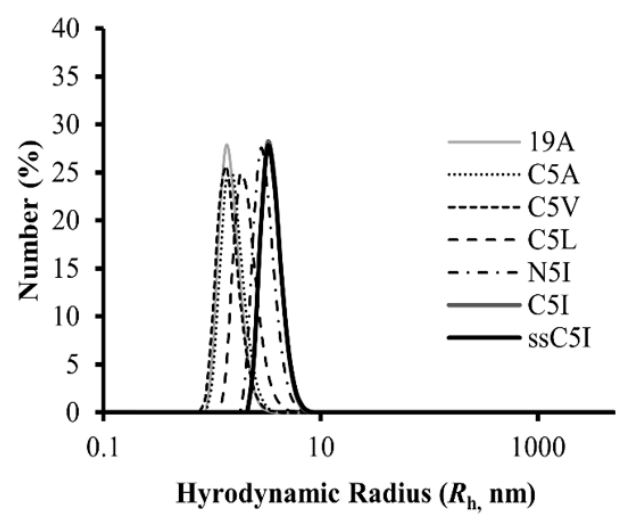

d)

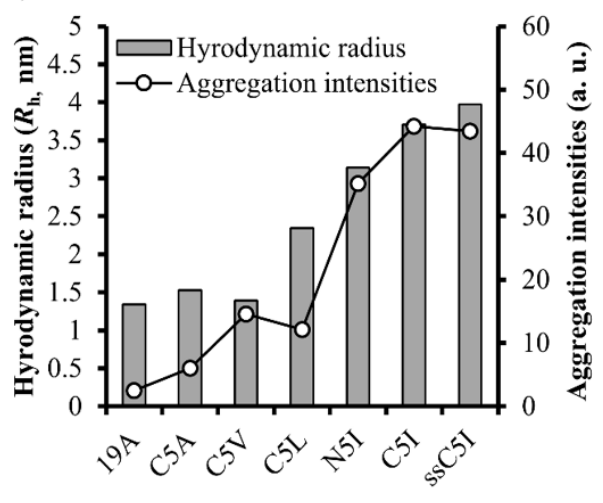




\section{Figure S2}

a)

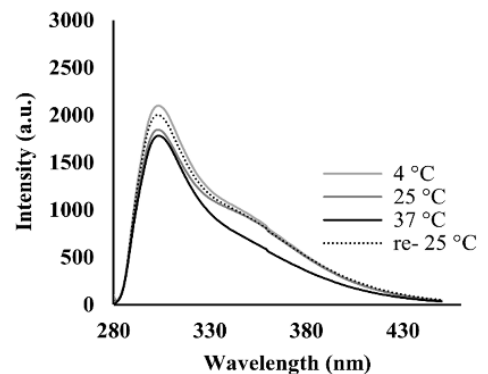

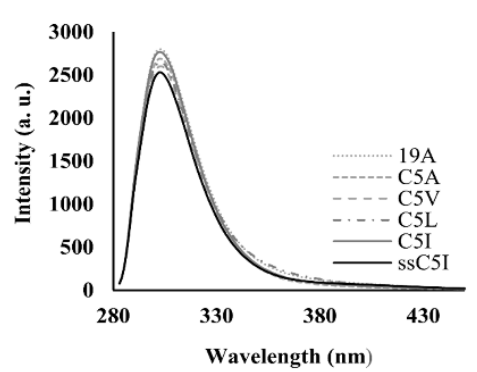

d)

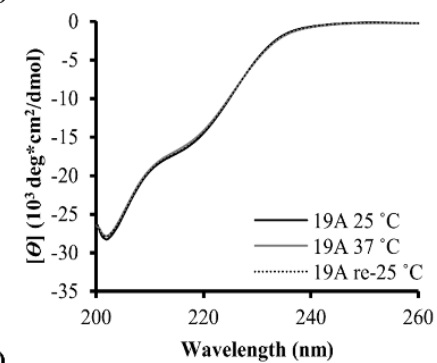

g)

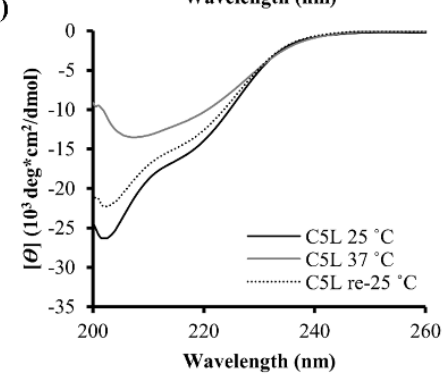

j)

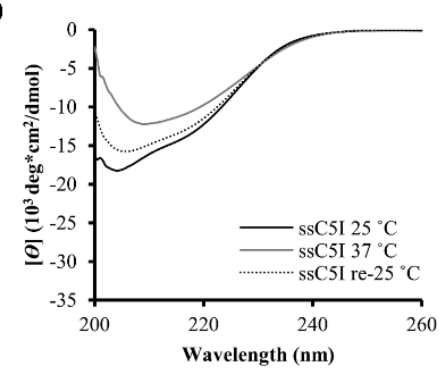

h)

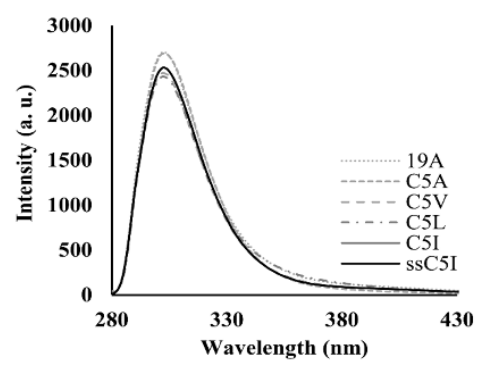

e)
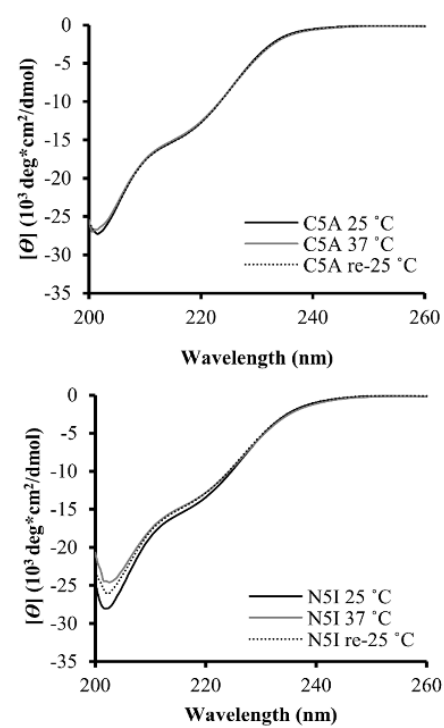

f)

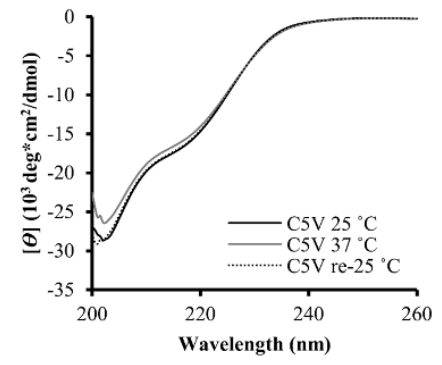

i)

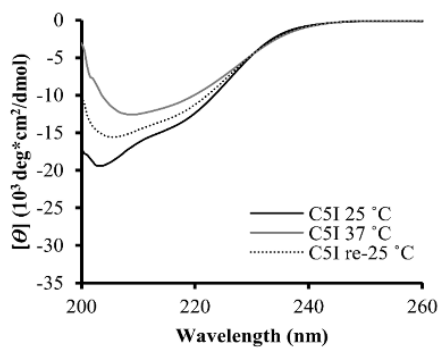




\section{Figure S3}

a)

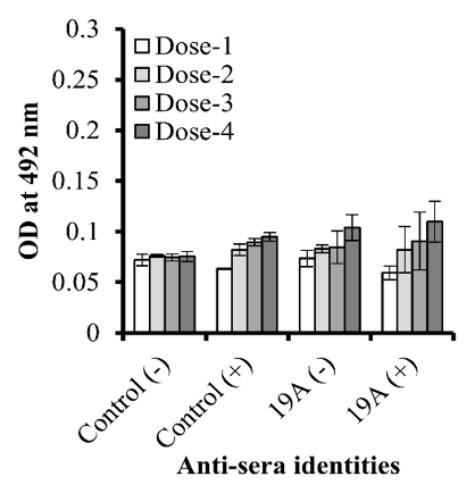

d)

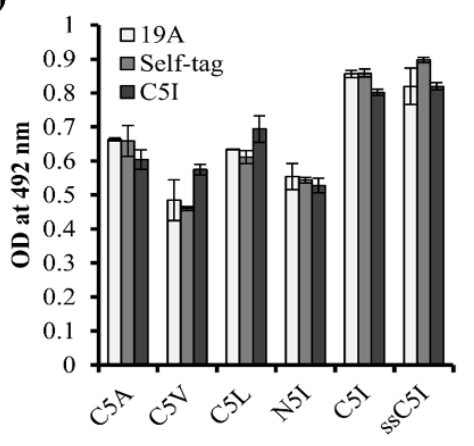

b)

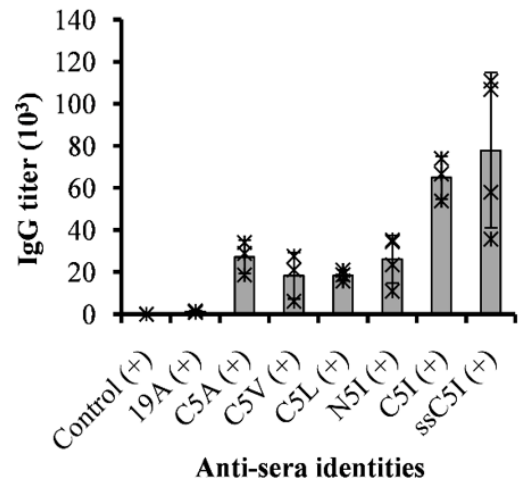

e)

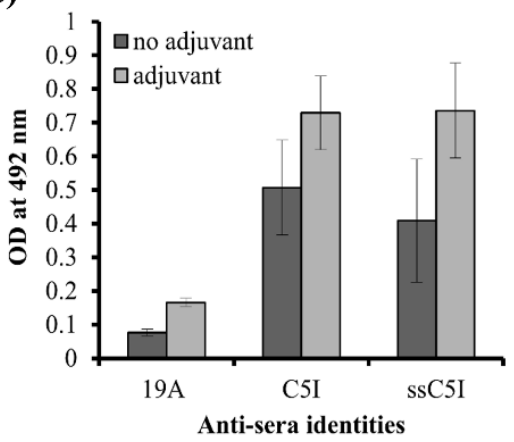

c)

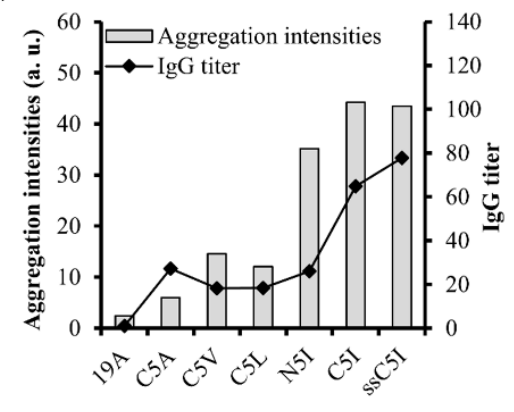

